Original Article

\title{
Viscum album homeopathic tinctures: phytochemical profile and antiproliferative activity.
}

\section{Carla Holandino ${ }^{1,3^{*}}$, Michelle Nonato de Oliveira Melo ${ }^{1}$, João Vitor da Costa Batista ${ }^{1}$, Venicio Feo da Veiga ${ }^{1}$, Adriana Passos Oliveira ${ }^{1}$, Cassiana Santos de Oliveira ${ }^{2}$, Mirio Grazi ${ }^{3}$, Hartmut Ramm $^{3}$, Claudia Dalla Torre ${ }^{4}$, Gerhard Schaller ${ }^{4}$, Claudia Scherr ${ }^{3}$, Maria Olga Kokornaczyk ${ }^{3}$, Konrad Urech ${ }^{3}$, Ulrike Weissenstein ${ }^{3}$, Stephan Baumgartner ${ }^{3}$}

1 Laboratório Multidisciplinar de Ciências Farmacêuticas, Faculdade de Farmácia, Universidade Federal do Rio de Janeiro, Rio de Janeiro - RJ, Brasil. *E-mail: cholandino@gmail.com; 2 Faculdade de Farmácia, Universidade de São Paulo, Ribeirão Preto, Brasil; 3 Society for Cancer Research, Hiscia Institute, Arlesheim, Switzerland; 4 Iscador AG, Arlesheim, Switzerland

\section{Abstract}

Background: The mistletoe Viscum album L. (Santalaceae) is a semi-parasitic plant that grows on different host trees. Although V. album antitumor activity is mainly associated with aqueous preparations, recently we showed antitumoral effects of homeopathic $\mathrm{V}$. album tinctures containing also the ethanolic soluble compounds [1].

Aims: to analyze the phytochemical profile of different Viscum album homeopathic tinctures as well as their in vitro effects in tumoral cells.

Methodology: The Viscum album samples (leaves, stems and berries) were collected in 2016 and 2017 (summer), and in 2018 (winter) at different locations in Switzerland. After harvest, they were immediately submitted to ethanolic extraction (45\% V/V) jusing homeopathic methodology [2, 3]. The following mother tinctures (MT) were prepared: $V$. album ssp. album growing on Malus domestica, Quercus sp. and Ulmus sp., V album ssp austriacum from Pinus sylvestris, and V. album ssp. abietis from Abies alba. The homedpath nat a $(1-3 \mathrm{dH} ; 6,12,30 \mathrm{dH})$ were prepared with the respective MT. The phytochemtcal profifes were analysed by High Performance Liquid Chromatography tandem Mass Spectroscopy, HPLC and Thin Layer Chromatography. MT prepared in 2016 were also submitted to the Pfeiffer's circular chromatography (PCC) [4]. The proliferation assay was performed by WST-1 [5] after incubation of tumoral cells (Yoshida and Molt-4) with nondynamized ( 0.5 to $0.05 \% \mathrm{v} / \mathrm{v}$ ) and dynamized MT. Apoptosis/necrosis was measured by flow cytometer (FACS) using Annexin V-FITC [5], and the cellular morphological aspects were analysed by light microscope.

Results and Discussion: The chemical analyses of MT identified the presence of phenolic acids, flavonoids, lignans, as principal compounds. Besides, the HPLC indicated higher viscotoxin concentration in the summer harvest of Abies alba, Malus domestica and Quercus (897, 475, 219 $\mu \mathrm{g} / \mathrm{mL}$ ), respectively. The PCC methodology permitted the MT differentiation. The higher levels of cellular mortality were attribute to Abies alba, Malus domestica and Quercus ( $\mathrm{p}<0.05$, ANOVA with Dunnett post hoc test), and it is might be related to their phytochemical profile as well as their higher viscotoxin contents. The dynamization process removed the toxicity of all MT, except after 
incubation with these same MT $(1 \mathrm{dH}$ and $2 \mathrm{dH})$. FACS analyses showed necrotic events with intensive cellular lysis, registered by optical microscopy.

Conclusion: The Viscum album mother tinctures presented promising antitumoral potential. The loss of cytotoxicity effects after dynamization could be related to denaturation reactions induced by the shaking process. To test this hypothesis, chemical analyses will be performed with 1 and $2 \mathrm{dH}$, in future investigations. Stability assessments of Viscum album MT will be done in order to guarantee the reproducible pharmaceutical parameters.

Keywords: Mistletoe (Viscum album L.), cancer, homeopathy, phytochemistry, cytotoxicity.

\section{References}

1. Mello, MNO; Oliveira, AP; Adalgisa, FW; Sampaio, RC; De Lima, CJ; Alves, FGO; Pereira, MGH; Veiga, VF; Capella, MAM; Rocha, LM; Holandino, C. Phenolic compounds from Viscum album Tinctures Enhanced Antitumor Activity in Melanoma Murine Cancer Cells. Saudi Pharmaceutical Journal, 26:311 - 322, 2018.

2. ANSM. Agence Nationale de Seócuriteó du Medicament et des Produits de Santeó. Pharmacopeóe Française, Preparationshomeopathiques. The General Chapters and General Monographs of the European Pharmacopoeia and Preamble of the French Pharmacopoeia apply. Mistletoe from the apple tree for homoeopathic preparations. 11ed., Paris, 2011, pages 1-4.
3. ANVISA. Agencia Nacional de Vigilancia Sanitaória. Farmacopeia Homeopaótica Brasileira, 3a $\mathbf{a}$ ed., Ed. ANVISA, Brasilia; 2011; pages 31-33.

4. Kokornaczyk, MO, Primavera, F, Luneia, R, Baumgartner, S. Analysis of soils by means of Pfeiffer's circular chromatography test and comparison to chemical analysis results. Biological Agriculture \& Horticulture, 2016. http://dx.doi.org/10.1080/01448 765.2016.1214889

5. Weissenstein, U; Kunz, Matthias; Urech, Konrad; Regueiro, U.; Baumgartner, S. Interaction of a standardized mistletoe (Viscum album) preparation with antitumor effects of Trastuzumab in vitro. BMC Complementary and Alternative Medicine, 16:271, 2016, DOI 10.1186/s12906-0161246-2.

Received: March 1, 2018. Accepted: April 26, 2018.

(C) International Journal of High Dilution Research.

Not for commercial purposes. 